\title{
Akses Pelayanan Kesehatan yang Tersedia pada Penduduk Lanjut Usia Wilayah Perkotaan di Indonesia
}

\author{
The Access to Available Health Services for Elderly People In Indonesian \\ Urban Areas
}

\author{
Roy Glenn Albert Massie ${ }^{1}$ \\ 1) Pusat Penelitian dan Pengembangan Sumber Daya dan Pelayanan Kesehatan, Jalan Percetakan Negara No. 29 Jakarta \\ 10560, Indonesia \\ Korespondensi: rgamassie@gmail.com
}

Submitted: 21 Desember 2018, Revised: 16 April 2019, Accepted: 29 April 2019

https://doi.org/10.22435/jpppk.v3i1.130

\begin{abstract}
Abstrak
Penelitian tentang akses lanjut usia (lansia) terhadap pelayanan kesehatan telah banyak dilakukan dengan menggunakan metode yang sama maupun berbeda. Diperlukan suatu hasil gabungan analisis penelitian dan dapat dijadikan inferensi pada parameter yang dapat diinterpretasi. Dalam kajian ini dilakukan meta-analisis akses kesehatan publik bagi lansia di wilayah perkotaan yang tersedia pada tingkat fasilitas kesehatan tingkat pertama. Diidentifikasi kata kunci dari topik yang ada pada kepustakaan melalui pembacaaan abstrak secara berulang kali. Dilakukan pencatatan hasil inferensi, kemudian dipilah sub-topik yang dipikirkan penting dan berhubungan. Ringkasan kepustakaan dibuat sesuai dengan urutan dan relevansi topik masing-masing variabel, yang disesuaikan dengan sub-topik terkait. Akses pelayanan kesehatan terhadap lansia sangat tergantung pada ketersediaan sumber daya kesehatan, peralatan yang memadai dan program yang sesuai. Lansia kurang memanfaatkan pelayanan kesehatan disebabkan oleh jarak fasilitas kesehatan yang cukup jauh dari tempat tinggalnya dan tidak ada yang mengantarnya. Masih ada lanjut usia yang tidak pernah memanfaatkan pelayanan kesehatan dasar gratis. Sebagian kecil lansia mengakses informasi promosi kesehatan melalui media sosial. Fasilitas umum yang sangat dibutuhkan oleh kelompok lansia namun masih kurang terkait ketersediaan tenaga, alat medis, obat, laboratorium dan kondisi fisik serta dana operasional puskesmas. Perlindungan terhadap sosial bagi lansia juga dilakukan oleh organisasi masyarakat dan keagamaan (misal kerjasama gereja dan kelurahan) dan bantuan program Corporate Social Responsibility (CSR) perusahaan. Kebijakan pemerintah dan sumber daya di fasilitas kesehatan mempengaruhi akses pelayanan kesehatan terhadap lansia. Perlindungan sosial dan pemberdayaan ekonomi beperan dalam peningkatan kualitas hidup lansia. Komunikasi, Informasi dan Edukasi Kemitraan Pemerintah dan swasta, termasuk LSM perlu dilakukan terus menerus. Dukungan dan bimbingan oleh Pemerintah Daerah melalui berbagai kegiatan promosi dan proteksi kesehatan pemenuhan akses pelayanan kesehatan bagi lansia melalui kerjasama lintas program dengan sektor terkait perlu tingkatkan.
\end{abstract}

Kata kunci: Lansia, Akses Pelayanan Kesehatan

\section{Abstract}

Researches on the access of the elderly to health services have been carried out by using the same or different methods. Therefore, a combined result of research analysis is needed and can be used as an inference and it can be interpreted. The objectives are to study through a meta-analysis of public health service for elderly through assess the available at the puskesmas level; to identify where the information and knowledge of health obtained by elderly; the decision making of elderly when they are suffering from illness, and the availability of health services for elderly at puskesmas, and the social empowerment and economic support. In the literatures and documents the keywords were identified and inferenced the results by creating sub-topics. The summary of 
the literature review was made and consented to the order and relevance of the topic in each variable, which is adjusted to the related sub-topics. Access to health care for the elderly is highly dependent on the availability of health resources, adequate equipment in the appropriate program. There are elderly who do not use the health services available at health facilities due to the distance of the health facilities that are quite far from where they live and there was no one drives them to health facility. Therefore, even the health service was free for charge, the elderly had not used it. Many elderly obtained a benefit of health promotion through the social media. In puskesmas there were lacks of availability of medical devices, drugs and medical supplies, laboratories, including the operational cost for eldery's health services. Public - private collaboration on social protection for elderly was existed such as from churches support including other social supports namely Corporate Social Responsibility program from private sector. The policies, infrastructures, and resources in the health facility were affected to the access of elderly. Social protection and economic empowerment have a potential role in improving the quality of life for the elderly. Improving the health service for elderly at puskesmas are urgently needed. Health services quality for elderly provided by public health institutions should be fulfilled particularly on the human resources capacity. Support and guidance by the local government through various health promotion and prevention activities and cross-program collaboration with related sectors should be boosted.

\section{Keywords: Elderly, Health Services Access}

\section{Pendahuluan}

Sejalan dengan meningkatnya usia harapan hidup maka akan terjadi perubahan struktur usia penduduk sebagai konsekuensi dari bertambahnya jumlah penduduk lanjut usia (lansia). Meningkatnya umur harapan hidup menyebabkan peningkatan jumlah lanjut usia, dimana pada tahun 2020 diperkirakan mencapai 28,8 juta jiwa. $^{1}$ Berbagai kebijakan telah dirumuskan oleh Kementerian Kesehatan dan implementasi program serta kegiatan dalam menunjang mutu kehidupan lansia. Implementasi dari program kesehatan terhadap lansia lebih memprioritaskan upaya pencegahan penyakit (preventif) dan peningkatan hidup sehat (promotif), tanpa mengabaikan upaya pengobatan (kuratif) dan rehabilitatif. Tujuan Program Kesehatan Lanjut Usia adalah meningkatkan derajat kesehatan lansia agar tetap sehat, aktif, mandiri dan berdaya guna baik bagi dirinya sendiri, keluarga maupun masyarakat. UU No. 36 Tahun 2009 Tentang Kesehatan pasal 138 menyatakan bahwa upaya pemeliharaan kesehatan bagi lansia harus ditujukan untuk menjaga agar tetap hidup sehat dan produktif secara sosial maupun ekonomi sesuai dengan martabat kemanusiaan. Pemerintah wajib menjamin ketersediaan pelayanan kesehatan dan memfasilitasi kelompok lansia untuk dapat tetap hidup mandiri dan produktif.

Penelitian tentang akses lansia terhadap pelayanan kesehatan telah banyak dilakukan dengan menggunakan metode yang sama maupun berbeda. Demikian pula dilakukan oleh peneliti yang berbeda maupun oleh peneliti yang sama, dan pada waktu yang berbeda, demikian juga sampel yang berbeda. Hal ini mengakibatkan hasil penelitian tersebut berlainan. Oleh karena itu, diperlukan suatu hasil gabungan analisis penelitian dan dapat dilakukan inferensi dengan parameter yang dapat diinterpretasi. Walaupun kajian ini berfokus pada substansi akses lansia terhadap pelayanan kesehatan yang disediakan oleh sektor publik di wilayah perkotaan, namun hasil kajian ini diharapkan dapat memberikan masukan dalam peningkatan pelayanan kesehatan melalui pengembangan kebijakan kesehatan terhadap lanjut usia baik di tingkat nasional, provinsi dan kabupaten/kota. Permasalahan dari kajian ini adalah bagaimana program kesehatan yang ditawarkan kepada lansia dapat diakses dari aspek informasi dan pengetahuan kesehatan dari lansia dan bagaimana mereka mengambil keputusan untuk berobat saat mengalami sakit. Adapun tujuannya yaitu mengkaji akses pelayanan kesehatan dari lansia terhadap program dan fasilitas publik yang tersedia wilayah perkotaan di Indonesia.

\section{Metode}

Kegiatan ini mengkaji hasil-hasil penelitian, kepustakaan-kepustakaan dan dokumendokumen yang berhubungan dengan akses lansia terhadap pelayanan kesehatan yang mengacu pada tujuan-tujuan khusus sebagai tema-tema yang akan dikembangkan ke dalam sub-tema sub-tema. Pendekatan kualitatif melalui pengembangan pedoman yang beisi pertanyaan-pertanyan yang sederhana ditanyakan saat verifikasi dinas kesehatan 
kota serta pemberi pelayanan kesehatan di fasilitas kesehatan tingkat pertama yang terpilih.

Elemen-elemen dari kerangka konsep kajian ini meliputi akses lansia terhadap pelayanan kesehatan, informasi dan pengetahuan yang didapat oleh lansia untuk dapat menolong dirinya sendiri, atau orang lain dalam menghadapi permasalahan yang ditimbulkan oleh penyakit yang diderita. Selanjutnya adalah pengambilan keputusan saat lansia menderita sakit.

Fasilitas kesehatan yaitu institusi kesehatan publik yang memberi pelayanan kesehatan pada konteks kajian ini adalah dinas kesehatan kota dan salah satu pusat kesehatan masyarakat pada wilayah terpilih serta program kesehatan khusus lansia yang diberikan. Demikian juga penunjang sosial dan ekonomi yang merupakan penunjang terhadap kesehatan lansia.

Analisis data yang terkumpul dari hal-hal di atas disusun dengan mengunakan tematik analisis. Tematik analisis adalah pengembangan sub-sub tema yang dipikirkan penting. Prosesnya adalah melalui identifikasi dan pengelompokan dari data-data yang dibaca dan dibaca berkali-kali merujuk pada komponen pada kerangka konsep. Pengelompokan sub-tema sub-tema pada penelitian ini berdasarkan dari data yang dikumpulkan baik berupa sekunder yang dikaji dan hasil verifikasi.

\section{Hasil dan Pembahasan}

Proses penuaan merupakan proses sepanjang hayat dimulai semenjak dalam kandungan dan berlanjut sampai memasuki usia lanjut. Kesehatan seseorang di usia lanjut merupakan cerminan dari keadaan hidup dan tindakan individu selama rentang kehidupannya. ${ }^{2}$ Lanjut usia mempunyai keterbatasan fisik dan kerentanan terhadap penyakit. Secara alami bertambahnya usia akan menyebabkan terjadinya perubahan degeneratif dengan manisfestasi beberapa penyakit. Demikian pula gerak dan mobilitas lanjut usia menjadi lebih lambat dibandingkan dengan kelompok umur yang lebih muda, termasuk juga kekuatannya. Secara mental, lanjut usia sering kali mempunyai perasan tertekan/depresi karena fisik yang lemah. Kemampuan ekonomi yang menurun karena sudah berhenti bekerja dan perasaan yang tersisih dari masyarakat karena berkurangnya kontak sosial.
Jumlah lansia di tahun 2025 diperkirakan akan mencapai sekitar 32 sampai 36 juta orang, atau 11,34 persen dari populasi penduduk. ${ }^{3}$ Hasil Riset Kesehatan Dasar tahun 2013, menunjukan bahwa pola penyakit pada lansia yang terbanyak adalah hipertensi $57,6 \%$, artritis $51,9 \%$ dan stroke $46,1 \%$ diikuti masalah kesehatan gigi dan mulut $19,2 \%$. Sementara penyebab kematian terbanyak pada lansia dari Laporan Badan Litbangkes tahun 2011 di $15 \mathrm{kab} /$ kota adalah stroke $24,6 \%$ dan penyakit jantung iskemik $12 \%{ }^{4}$ Lansia bukan merupakan suatu penyakit, tetapi lansia sangat rentan terhadap penyakit yang bersifat menahun/jangka panjang dan berbahaya seperti penyakit kardiovaskular, stroke, kanker, diabetes, gangguan muskuloskeletal dan penyakit mental. Hal ini dikarenakan pada lansia terjadi penurunan berbagai fungsi tubuh sehingga akan meningkatkan/mempengaruhi masalah kesehatan pada diri lansia tersebut. ${ }^{5}$

Masalah utama bagi para lanjut usia adalah pemenuhan kebutuhan pelayanan kesehatan, oleh karena itu perlu dikembangkan pelayanan kesehatan yang lebih mengutamakan upaya peningkatan, pencegahan, dan pemeliharaan kesehatan disamping upaya penyembuhan dan pemulihan. ${ }^{6}$ Untuk mencapai tujuan di atas perlu diketahui akses lansia terhadap pelayanan kesehatan, demikian pula diperlukan antara lain data dari mana lansia mendapatkan sumber informasi kesehatan dan pengetahuan terhadap pemahaman kesehatan, kemampuan lansia dalam mengambil keputusan pada saat menderita sakit, dan diketahuinya faktorfaktor penunjang sosial untuk kesehatan lansia.

\section{Akses Terhadap Pelayanan Kesehatan}

Lansia mempunyai hak yang sama dalam kehidupan bermasyarakat, berbangsa dan bernegara. Sebagai penghormatan dan penghargaan kepada lansia diberikan hak untuk meningkatkan kesejahteraan yang meliputi: pelayanan keagamaan dan mental spiritual, pelayanan kesehatan, pelayanan kesempatan kerja, pelayanan pendidikan dan pelatihan, kemudahan dalam penggunaan fasilitas, sarana, dan prasarana umum, kemudahan dalam layanan dan bantuan hukum, perlindungan sosial dan bantuan sosial (UU No. 13 Tahun 1998). Dalam bidang kesehatan peran serta dari pemerintah, swasta, dan masyarakat dalam upaya 
peningkatan kesejahteraan lansia sangat dibutuhkan. Demikian pula dengan akses layanan kesehatan yang berkualitas yang komprehensif penting untuk pencapaian kesetaraan kesehatan dan untuk meningkatkan kualitas hidup sehat bagi lanjut usia. Akses pelayananan kesehatan terhadap lanjut usia sangat tergantung pada ketersediaan sumber daya kesehatan, peralatan yang memadai dalam program yang sesuai.

Meningkatkan akses ke pelayanan kesehatan untuk lanjut usia telah menjadi tujuan kebijakan publik yang penting selama beberapa dekade. Banyak inisiatif kebijakan telah dibuat oleh pemerintah baik di tingkat pusat maupun provinsi dan kabupaten/kota untuk pelayanan kesehatan terhadap lansia. ${ }^{7}$ Banyak bukti yang menunjang bahwa lansia kurang beruntung terhadap akses mereka ke layanan kesehatan didasarkan pada penelitian yang meneliti hubungan antara bertambahnya usia dan pemanfaatan layanan spesialis dalam perawatan sekunder dan tersier. ${ }^{8}$ Demikian pula dengan kemudahan dalam menjangkau lokasi fasilitas kesehatan berhubungan dengan faktor keamanan atau keselamatan bagi lansia. Jika lansia merasa aman atau merasa mudah untuk menjangkau lokasi posyandu tanpa harus menimbulkan kelelahan atau masalah yang lebih serius, maka hal ini dapat mendorong minat atau motivasi lansia untuk berkunjung ke fasilitas kesehatan.

Ditemukan ada lansia kurang memanfaatkan pelayanan kesehatan yang ada di fasilitas kesehatan disebabkan oleh jarak fasilitas kesehatan yang cukup jauh dari tempat tinggalnya dan tidak ada yang mengantarnya. Kondisi ini diketahui pada tahap verifikasi.

Akses ke pelayanan kesehatan bermakna juga pada penggunaan tepat waktu layanan kesehatan pribadi untuk mencapai hasil kesehatan yang terbaik. Dalam meningkatkan akses pelayanan kesehatan bagi lansia diperlukan berapa langkah yang berbeda yaitu mendapatkan kesempatan masuk ke dalam sistem pelayanan kesehatan; dapat mengakses tempat pelayanan kesehatan dan dapat berkomunikasi dan mempercayai pemberi pelayanan kesehatan. ${ }^{9}$ Keputuasan Menteri Kesehatan No. 279/Menkes/SK/IV/2006) menyebutkan bnahwa layanan kesehatan terhadap lansia yang tersedia di puskesmas antara lain berupa homecare/perkesmas (perawatan kesehatan masyarakat), poliklinik khusus lansia, dan kegiatan posyandu lansia. Dari hasil verifikasi di Puskesmas Pangolombian Kecamatan Tomohon Selatan Kota Tomohon terhadap pelayanan kesehatan lansia belum berjalan dengan baik dan maksimal. Pelayanan homecare yang merupakan tugas dan tanggungjawab program perkesmas tidak dilakukan secara rutin. padahal program ini harusnya dapat menjangkau para lansia yang tidak dapat menjangkau puskesmas oleh karena keterbatasan fisik mereka.

Poli khusus untuk para lansia juga belum tersedia, dimana seharusnya poli lansia disiapkan sebagai wadah untuk para lansia dapat memeriksakan diri mereka dan dapat melakukan konseling secara maksimal serta petugas dapat memberikan Komunikasi Informasi dan Edukasi geriatri kepada para lansia.

\section{Informasi dan Pengetahuan Kesehatan}

Informasi dan pengetahuan kesehatan adalah merupakan kemampuan kognitif yang paling rendah namun sangat penting karena dapat membentuk prilaku seseorang Peningkatan pengetahuan memiliki hubungan yang positif dengan perubahan perilaku. Dimana pengetahuan dapat diperoleh melalui pendidikan dan penyuluhan-penyuluhan kesehatan. ${ }^{10}$ Komunikasi antara pasien dan tenaga medis baik dokter maupun perawat adalah merupakan bentuk pertukaran informasi yang ada pada saat lansia melakukan pemeriksaan kesehatan di fasilitas kesehatan. Beberapa studi yang terfokus pada, perilaku informasi kesehatan pada populasi minoritas ada banyak peluang untuk meningkatkan kesadaran akan kesehatan dari perilaku lanjut usia yaitu mereka yang berusia 85 tahun atau lebih. ${ }^{11,12}$

Pada verifikasi lansia sangat tertarik terhadap promosi kesehatan tempat paling banyak mendapatkan informasi kesehatan adalah melalui media massa, dan kelompok lansia lebih dominan menerapkan perilaku sehat dari hasil promosi kesehatan dibandingkan usia yang lebih muda. Informasi dan pengetahuan yang diperoleh oleh lanjut usia antara lain dari media yang meliputi media cetak booklet, leaflet, flayer, flipchart, rubrik, poster, media elektronik meliputi TV, radio, video, dan film. Namun demikian pelayanan kesehatan terhadap lansia belum dilaksanakan secara maksimal. 
Puskesmas merupakan fasilitas pelayanan kesehatan yang menyelenggarakan upaya kesehatan masyarakat dan upaya kesehatan perseorangan tingkat pertama dengan lebih mengutamakan upaya promotif dan preventif untuk mencapai derajat kesehatan masyarakat yang setinggi-tingginya di wilayah kerjanya (Permenkes No 75 2014). Puskesmas juga merupakan salah satu tempat dari lanjut usia untuk mendapatkan informasi tentang kesehatan melalui pelayanan kesehatan yang diberikan khususnya promosi dan pencegahan kesehatan.

Permenkes, Nomor 67 Tahun 2015 menyatakan bahwa pelayanan kesehatan lanjut usia di puskesmas antara lain meliputi: pengkajian paripurna lanjut usia; pelayanan kesehatan bagi lanjut usia sehat; dan pelayanan kesehatan bagi pasien geriatri Informasi kesehatan dan pengetahuan sangat penting untuk menjaga kesehatan pada lansia, agar supaya para lansia berperilaku hidup sehat sehingga mereka dapat berdaya dan sejahtera, dan hal ini juga merupakan bagian dari tugas dan tanggung jawab puskesmas.

Hasil penelitian menunjukkan bahwa lansia sangat tertarik pada promosi kesehatan. Kelompok lansia lebih dominan menerapkan perilaku sehat dari hasil promosi kesehatan dibandingkan usia yang lebih muda. ${ }^{13,14}$ Verifikasi pada Puskesmas Pangolombian Kecamatan Tomohon Selatan Kota Tomohon, pemanfaatan media sebagai sumber informasi kesehatan yaitu berupa poster-poster yang direkatkan pada dinding bangunan tidak dimanfaatkan oleh pengunjung khususnya lansia. Hal tersebut disebabkan lansia hanya berkunjung untuk mendapatkan pengobatan. Demikian pula informasi pada fasilitas kesehatan belum tersedia dan peningkatan peran petugas kesehatan yang ada pada fasiltias kesehatan dalam pemberian informasi dan pengetahuan terhadap lansia.

Pelayanan kesehatan terhadap lansia yang terselenggara di Puskesmas Pangolombian baru berupa Posyandu Lansia yang di dalamnya ada kegiatan senam bagi para lansia, penyuluhan untuk mendapatkan informasi dan pengetahuan kesehatan, dan kegiatan pemeriksaan kesehatan dilakukan secara rutin sebulan sekali di lima kelurahan wilayah kerja puskesmas tersebut.
Pengetahuan memegang peran penting untuk mengubah perilaku seseorang ke arah yang lebih baik. ${ }^{15}$ Pengetahunan kesehatan dari lansia dipengaruhi oleh bahwa faktor-faktor yang mempengaruhi pengetahuan antara lain yaitu pendidikan, usia, pengalaman, media massa dan penyuluhan. Pada umumnya setelah seseorang memasuki tahap lansia maka akan mengalami penurunan fungsi kognitif (proses belajar, persepsi, pemahaman, pengertian, dan lain-lain) dan psikomotor (gerakan, tindakan, koordinasi). ${ }^{16}$

Pengetahuan yang rendah merupakan salah satu faktor internal yang mempengaruhi motivasi lansia mengunjungi fasilitas kesehatan. Lansia yang memiliki pengetahuan tinggi akan mempunyai motivasi yang besar untuk datang dan memanfaatkan fasilkitas kesehatan dan sebaliknya bagi lansia yang memiliki pengetahuan rendah. ${ }^{17}$ Tingkat pendidikan dan pengetahuan yang rendah juga mempengaruhi keputusan para lansia untuk berobat saat mereka sakit, pengobatan-pengobatan alternatif dengan iming-iming kesembuhan secara prima hanya dengan menggunakan satu produk yang dapat menyembuhkan berbagai macam penyakit juga mempengaruhi para lansia di wilayah kerja Puskesmas Pangolombian saat mereka mencari kesembuhan.

Hasil penelitian menunjukkan 54\% proporsi lanjut usia mempunyai tingkat pemanfaatan pelayanan kesehatan dasar gratis. Sebagian besar lanjut usia yang tidak pernah memanfaatkan pelayanan kesehatan dasar gratis. Puskesmas mengemukakan alasan tidak tahu tentang adanya pelayanan kesehatan dasar gratis puskesmas. Sebagian besar lanjut usia berpendidikan rendah dan tidak bekerja, berpersepsi kebutuhan pelayanan kesehatan tinggi, persepsi kualitas pelayanan puskesmas rendah (terutama pada dimensi assurance dan tangible) dan persepsi aksesibilitas ke puskesmas mudah. ${ }^{18}$ Sebagian besar lansia di Puskesmas Pangolombian masih memilih untuk melakukan pengobatan sendiri apabila mereka sudah tidak mampu menjangkau akses pelayanan, dan kurangnya dukungan dari keluarga untuk membantu lansia membawa ke fasilitas kesehatan untuk mendapatkan pengobatan pada saat menderita sakit. 
Kendala yang dihadapi lansia dalam mengikutikegiatan posyandu antara lain pengetahuan lansia yang rendah tentang manfaat posyandu. Pengetahuan lansia akan manfaat posyandu ini dapat diperoleh dari pengalaman pribadi dalam kehidupan sehari-harinya. Dengan menghadiri kegiatan posyandu, lansia akan mendapatkan penyuluhan tentang bagaimana cara hidup sehat dengan segala keterbatasan atau masalah kesehatan yang melekat pada mereka. Dengan pengalaman ini, pengetahuan lansia menjadi meningkat, yang menjadi dasar pembentukan sikap dan dapat mendorong minat atau motivasi mereka untuk selalu mengikuti kegiatan posyandu lansia.

\section{Kemampuan Mengambil Keputusan Saat Menderita Sakit}

Kemampuan lanjut usia dalam mengambil keputusan pada saat menderita sakit sangat berhubungan dengan konsep diri. Pengertian Konsep diri adalah semua perasaan, kepercayaan, dan nilai yang diketahui individu tentang dirinya dan mempengaruhi individu dalam berhubungan dengan orang lain. Konsep diri dipelajari sejalan dengan kehidupan seseorang, sebagai hasil pengalaman hidup dalam dirinya sendiri, dengan orang terdekat, dan dengan realitas dunia. Konsep diri ini dapat berubah akibat kondisi sakit, yang berhubungan dengan perubahan gambaran diri selama sakit serta perubahan peran sosial di masyarakat. ${ }^{19}$ Konsep diri pada lansia adalah cara pandang lansia melihat dirinya dan lingkungan di sekitarnya yang terbentuk dari lahir dan pengalaman lansia itu sendiri termasuk dalam pengambilan keputusan dalam keadaan sakit.

Penurunan konsep diri akan mempengaruhi pola pemikiran lanjut usia terhadap perilakunya. Perubahan konsep diri pada lanjut usia terutama disebabkan oleh kesadaran subyektif yang terjadi yang sejalan dengan bertambahnya usia. Lanjut usia akan banyak mengalami perubahan fisik kemampuan dan fungsi tubuh yang akan mengkibatkan tidak stabilnya konsep diri. ${ }^{20} \mathrm{Hal}$ ini sangat berpengaruh terhadap kemampuan mengambil keputusan saat menderita sakit.

Pengambilan keputusan saat menderita sakit adalah persepsi lansia terhadap kemampuan mereka untuk mengelola masalah kesehatan, termasuk sejauh mana mereka dapat mendiagnosa dan mengelola masalah sendiri atau perlu mencari bantuan medis. ${ }^{21}$

Verifikasi yang dilakukan ditemukan persoalan kesehatan lansia yang berusia 65-74 tahun paling dominan adalah disabilitas, radang sendi, katarak, diare dan stroke. Sedangkan lansia yang berumur di atas 75 tahun terutama mengalami masalah disabilitas, radang sendi, katarak, stroke, diare dan ISPA. Berbagai cara dilakukan oleh para lansia ketika mereka sakit. Ada yang langsung memeriksakan diri ke fasilitas kesehatan terdekat apakah itu puskesmas maupun dokter praktek mandiri, atau mereka mengobati sendiri dengan membeli obat di warung yang menyediakan obat ataupun di apotik, ataupun ada yang memilih untuk melakukan pengobatan secara alternatif lainnya. Pilihan mereka dalam mengambil keputusan saat sakit dipengaruhi oleh faktor keluarga, sosial ekonomi dan tingkat pendidikan para lansia itu sendiri.

Tingkat pendidikan dan pengetahuan yang rendah juga mempengaruhi keputusan para lansia untuk berobat saat mereka sakit, pengobatan-pengobatan alternatif dengan iming-iming kesembuhan secara prima hanya dengan menggunakan satu produk yang dapat menyembuhkan berbagai macam penyakit juga mempengaruhi para lansia di wilayah kerja Puskesmas Pangolombian saat mereka mencari kesembuhan.

\section{Fasilitas dan Program Pelayanan Kesehatan Khusus Lansia}

Kebijakan Kementerian Kesehatan dalam pelayanan kesehatan lanjut usia bertujuan untuk meningkatkan derajat kesehatan lanjut usia yang berkualitas melalui penyediaan sarana pelayanan kesehatan yang ramah bagi lanjut usia untuk mencapai lanjut usia yang berdayaguna bagi keluarga dan masyarakat. Upaya yang dikembangkan untuk mendukung kebijakan tersebut antara lain meningkatkan upaya kesehatan bagi lanjut usia di pelayanan kesehatan dasar dengan pendekatan Pelayanan santun lanjut usia, meningkatkan upaya rujukan kesehatan bagi lanjut usia. ${ }^{22}$

Fasilitas umum yang sangat dibutuhkan oleh kelompok lansia ini adalah sebuah fasilitas yang menyediakan pelayanan di bidang kesehatan 
yang didukung oleh sumber daya yang tersedia di masyarakat, terjangkau oleh masyarakat diterima oleh masyarakat.

Program kesehatan lanjut usia khususnya pada fasilitas kesehatan puskesmas meliputi aspek pembinaan dan pelayanan kesehatan, dan aspek manajerial. ${ }^{23}$ Penyediaan layanan kesehatan sebagian besar diberikan dalam konteks pengobatan modern yaitu menghilangkan rasa sakit dan memberikan perawatan, dan bila tidak ada perubahan penyediaan pelayanan perawatan nampak berkurang. Ada kebutuhan untuk perubahan paradigma dari model medis ke model sosial dalam memberikan pelayanan kesehatan. ${ }^{24}$

Salah satu wujud pelayanan kesehatan dari pemerintah kepada kelompok lansia yaitu melalui Pos Pelayanan Terpadu (Posyandu) Lansia. Posyandu Lansia atau juga biasa disebut dengan istilah Pos Pembinaan Terpadu (Posbindu) Lansia merupakan suatu bentuk keterpaduan pelayanan kesehatan dasar terhadap lansia di tingkat desa dalam masing-masing di wilayah kerja puskesmas. Tujuan dari Posyandu Lansia secara garis besar adalah meningkatkan jangkauan pelayanan kesehatan lansia di masyarakat, sehingga terbentuk pelayanan kesehatan yang sesuai dengan kebutuhan lansia ${ }^{23}$. Posyandu dipandang sangat bermanfaat bagi masyarakat namun keberadaannya di masyarakat kurang berjalan baik.

Posyandu Lansia yang kini termasuk upaya pengembangan puskesmas memiliki program atau upaya terkait penyuluhan-penyuluhan kesehatan, pencegahan penyakit, dan pemeriksaan kesehatan seperti mengukur tinggi badan, penimbangan berat badan, pemeriksaan tekanan darah, gula darah, hemoglobin dan kolesterol untuk mengetahui lebih awal penyakit yang diderita (deteksi dini) atau ancaman masalah kesehatan yang dihadapi sehingga hal tersebut dapat di antisipasi ${ }^{23}$.

Terdapat upaya-upaya yang dilakukan oleh dinas kesehatan dan puskesmas dalam rangka memelihara dan mengatasi masalah kesehatan bagi lanjut usia sementara berjalan, kegiatan ini diketahui pada verifikasi. Bentuknya antara lain berupa kegiatan senam bagi para lansia, penyuluhan untuk mendapatkan informasi dan pengetahuan kesehatan, dan kegiatan pemeriksaan kesehatan dilakukan secara rutin sebulan sekali di lima kelurahan wilayah kerja puskesmas tersebut. Tenaga medis dalam menjalankan program pembinaan ini belum memadai.

Ketersediaan sumber daya kesehatan yang khusus menangani masalah kesehatan lansia belum tersedia diketahui pada verifikasi selanjutnya. Tenaga kesehatan merangkap pekerjaan dari beberapa program yang ada di puskemas. Demikian pula, dukungan dana belum mencukupi dan peralatan khusus untuk pemeriksaaan kesehatan bagi lansia belum tersedia. Kurangnya ketersediaan tenaga, alat medis, obat, laboratorium dan kondisi fisik serta dana operasional puskesmas menjadi hambatan yang dihadapi oleh puskesmas dalam meningkatkan akses lanjut usia dalam pemanfaatan pelayanan kesehatan untuk mereka khususnya untuk mendapatkan pelayanan kesehatan.

Sumber daya kesehatan saat ini ditargetkan untuk program jangka pendek untuk orang dewasa yang lebih tua dan yang mengidap beberapa kronis kondisi, seperti yang difokuskan pada pengurangan hari rawat inap ${ }^{25}$. Pada sisi lain, sebagian besar perawatan kesehatan khususnya di fasilitas tingkat pertama yang diselenggarakan dalam bentuk perawatan akut dan kronis, modelnya yang tidak memenuhi kebutuhan banyak pasien terutama pasien lansia dengan penyakit kronis. Selain itu, meskipun pelayanan kesehatan baik dimana mayoritas lansia tinggal, mereka hanya menerima sebagian kecil dari sumber daya perawatan kesehatan ada. ${ }^{26}$

\section{Perlindugan Sosial dan Pemberdayaan Ekonomi Terhadap Lanjut Usia}

Faktor sosial dan ekonomi turut berpengaruh dalam pengambilan keputusan dari lansia untuk berkunjung ke fasilitas kesehatan. Ada anggapan bahwa pengobatan pada fasilitas kesehatan mahal, ditambah dengan pemahaman bahwa dengan berobat mengunakankan Jaminan Kesehatan Nasional, pelayanan kesehatan yang diberikan tidak maksimal. Hal tersebut berkontribusi pada pengambilan keputusan para lansia saat sakit.

\subsection{Perlindungan Sosial}

Perlindungan sosial merupakan sebuah aspek yang tidak terpisahkan pada pemeliharaan dan peningkatan kesehatan lansia. Dukungan sosial dapat dianggap sebagai sesuatu keadaan yang bermanfaat, pemberian bantuan bagi individu yang 
diperoleh dari orang lain yang dapat dipercaya dan sebagai keberadaan dan kesediaan orang-orang yang berarti, yang dapat dipercaya untuk membantu, mendorong, menerima, dan menjaga individu. ${ }^{27}$

Demikian juga ketahanan ekonomi yang merupakan penunjang terhadap kesehatan lansia. Perlindungan sosial adalah sebuah sistem yang disediakan melalui serangkaian kebijakan publik untuk meminimalkan dampak dari guncangan ekonomi dan sosial yang dapat disebabkan oleh hilangnya atau berkurangnya pendapatan sebagai akibat dari, penyakit yang diderita, kehamilan, kecelakaan kerja, pengangguran, disabilitas, usia tua, atau kematian. Sistem perlindungan sosial yang komprehensif diantaranya dapat terdiri dari program jaminan sosial, bantuan sosial, serta mencakup skema-skema bantuan dan jaminan dana yang didanai oleh pemerintah maupun kontribusi dari pesertanya. $^{28}$

Peran Badan Perencanaan Pembangunan Daerah (Bappeda) merupakan leading sector dalam perencanaan pada tingkat pemerintahan di kabupaten dan kota. Demikian pula dalam mengkoordinasikan perumusan kebijakan, strategi, program, kegiatan dan langkah langkah yang diperlukan dalam penanganan lanjut usia sesuai pedoman strategi, program dan kegiatan lansia melalui kegiatan dan kebijakan Satuan Kerja Perangkat Daerah dalam hal ini Dinas Kesehatan dan instansi-instansi yang berhubungan lainnya. Termasuk contohnya dinas sosial melalui pelayanan, perlindungan dan bantuan untuk kesejahteraan lansia.

Undang-Undang Nomor 40 Tahun 2004 tentang Sistem Jaminan Sosial Nasional, Penduduk Indonesia diamanatkan untuk memiliki suatu sistem jaminan sosial yang lebih komprehensif. Sistem jaminan sosial ini bertujuan untuk memberikan jaminan keterpenuhan kebutuhan dasar hidup yang layak bagi setiap penduduk peserta program jaminan sosial termasuk lansia.

Pelayanan sosial dan bantuan bagi penduduk lanjut usia merupakan perlindungan dan kesejahteraan sosial bagi penduduk lanjut usia dilakukan melalui pelayanan dalam panti, luar panti, kelembagaan lanjut usia dan perlindungan sosial, serta aksesibilitas untuk lanjut usia. Sistem pelayanan dalam panti meliputi pelayanan sosial reguler dalam panti, pelayanan harian (day care), subsidi silang, subsidi panti, dan multi layanan serta rujukan. Sistem pelayanan luar panti meliputi pendampingan dan perawatan lanjut usia di rumah (home hare), foster care, pelayanan harian (day care services), Usaha Ekonomi Produktif (UEP), KUBe, serta pembinaan UEP menjelang purnakaryawan (pralanjut usia). ${ }^{28}$

Peran swasta terhadap pelayanan dan perlindungan terhadap lansia baik dari organisasi masyarakat dan keagamaan sebagai penunjang sosial dapat dilaksanakan. Verifikasi yang dilakukan ditemukan adanya kerjasama dengan gereja dan kelurahan. Dimana kelompok-kelompok lansia pada posyandu lansia juga adalah mereka yang merupakan kelompok lansia gereja pada berbagai denominasi dan kelurahan.

Penunjang sosial lainnya pada kesehatan lansia, adanya bantuan pihak Pertamina Geothermal sebagai Corporate Social Responsibility (CSR) yang membantu pemberian alat periksa gula darah pada posyandu lansia di beberapa kelurahan wilayah kerja dari Puskesmas Pangolobian.

\subsection{Pemberdayaan Ekonomi}

Lansia pelu memiliki sumber pendapatan untuk mendukung kehidupannya agar sejahtera. ${ }^{29}$ Dengan bertambahnya umur menjadi tua adalah bukan menjadi penghambat untuk tetap menjalankan usaha yang menghasilkan pendapatan untuk memperkuat ekonomi keluarga dan kebutuhan pribadi dari lansia.

Pendapatan merupakan faktor yang paling penting yang terkait dengan akses terhadap peyanan kesehatan terhadap lansia, meskipun ada asuransi kesehatan. Penelitian menunjukkan bahwa pendapatan adalah prediktor kuat dari akses ke perawatan kesehatan pada orang tua, independen $\operatorname{ras}^{30}$. Ada penelitian mengindikasikan bahwa ada hambatan seperti biaya, transportasi, kurangnya informasi dalam hal mendapatkan pelayanan kesehatan terhadap lansia. ${ }^{31}$ Pemberdayaan lansia melalui usaha ekonomi produktif antara lain dapat terpenuhinya kebutuhan lansia sehari-hari, melakukan kegiatan sosial, mendukung kesehatan, serta memenuhi kebutuhan batin lansia. Kedua, adanya peningkatan pendapatan lansia yang menjalankan usaha. ${ }^{22}$ Pemberdayaan ekonomi lansia yang berhasil dan berkelanjutan membutuhkan partisipasi aktif dari otoritas setempat, agama baik di 
kabupaten/kota, kecamatan dan di daerah kelurahan atau pedesaan. ${ }^{32}$

Diperlukan strategi untuk kesempatan kerja karena kehidupan yang produktif dapat meningkatkan kesejahteraan fisik dan mental untuk tetap aktif di usia tua. Penghasilan lansia dan berbagi pengalaman juga dapat memastikan partisipasi yang lebih besar pada kesehatan lansia dalam kehidupan masyarakatnya. ${ }^{33}$

\section{Kesimpulan}

Akses pelayananan kesehatan terhadap lanjut usia sangat tergantung pada kebijakan kesehatan pemerintah dan sumber daya yang ada pada fasilitas kesehatan. Pada beberapa kepustakaan dan hasil verifikasi mengindikasikan bahwa pelayanan kesehatan dari puskesmas masih terbatas dan belum mencakup kebutuhan kesehatan dari lansia.

Kelompok lansia menerapkan perilaku sehat dari hasil promosi kesehatan dan hal tersebut mempengaruhi kemampuan mengambil keputusan pada saat menderita sakit. Walaupun pilihan dalam mengambil keputusan saat sakit dipengaruhi juga oleh faktor keluarga dan tingkat pendidikan para lansia itu sendiri.

Fasilitas kesehatan untuk memberikan pelayanan kesehatan dasar terhadap lansia adalah fasilitas puskesmas dan Pos Pelayanan Terpadu (Posyandu) Lansianya atau yang dikenal sebagai Pos Pembinaan Terpadu (Posbindu) Lansia. Beberapa penelitian mengindikasikan belum berjalan dengan baik pelayanan kesehatan terhadap lansia di fasilitas-fasilitas kesehatan, demikian juga hal sama pada saat dilakukan verifikasi.

Penunjang sosial terhadap lanjut usia berperan dalam pelayanan kesehatan. Pemberdayaan sosial untuk pelayanan kesehatan bentuknya dapat berupa Corporate Social Responsibility (CSR) yang adalah komitmen dunia usaha untuk kontribusi dalam pembangunan ekonomi berkelanjutan, bekerja dengan karyawan dan perwakilan mereka, komunitas lokal serta masyarakat luas untuk meningkatkan kualitas hidup yang bermanfaat bagi dunia usaha dan bagi pembangunan. ${ }^{34}$ Demikian juga CSR terhadap program-program lansia yang berada dalam jangkauan perusahan-perusahan yang ada di sekitar wilayah fasilitas kesehatan tingkat pertama.

\section{Saran}

Pelayanan kesehatan terhadap lansia oleh institusi kesehatan publik dalam hal ini fasilitas kesehatan tingkat pertama yang berupa pelayanan homecare/perkesmas (perawatan kesehatan masyarakat), poliklinik khusus lansia, dan kegiatan posyandu lansia perlu ditingkatkan melalui pemenuhan sumber daya manusia dan peralatan.

Menjadikan pemberdayaan keluarga melalui intensif komunikasi oleh petugas kesehatan di puskesmas, agar supaya pemberian informasi kesehatan kepada lansia dapat terlaksana.

Perlu disediakan sarana informasi kesehatan pada fasilitas kesehatan antara lain jam buka, proses pendaftaran, biaya pengobatan dan prosedur administrasi untuk asuransi harus disediakan dengan cara yang sesuai dengan usia. ${ }^{20}$ Demikian pula pemberian informasi kepada lansia dalam berbagai bentuk Komunikasi Informasi dan Edukasi terhadap lansia sangat diperlukan.

Pemerintah dan masyarakat, lembaga pelayanan sosial, fasilitas perawatan kesehatan, dan sektor terkait lainnya dengan asas kemitraan untuk bersama-sama melakukan pembinaan dalam rangka peningkatan kualitas hidup lansia. perlu mempersiapkan pelayanan kesehatan yang memadai dan pelayanan yang berkualitas. Dengan meningkatnya populasi dari lansia diperlukan kebutuhan kesehatan lansia.

Pemerintah daerah melalui puskesmas harus memberikan dukungan dan bimbingan melalui berbagai kegiatan promosi dan proteksi kesehatan dalam memelihara dan meningkatkan kesehatannya agar tetap sehat dan mandiri. Demikian pula dapat melakukan kerjasama lintas program dengan sektor terkait di tingkat wilayah tertentu da diarahkan ke solusi jangka panjang yang selaras dengan kebutuhan dan preferensi dari lansia.

\section{Ucapan Terima Kasih}

Penulis mengucapkan terima kasih kepada Kepala Pusat Humaniora, Kebijakan Kesehatan dan Peran Serta Masyarakat Badan Penelitian dan Pengembanhgan Kesehatan. Kementerian RI 
Jakarta; Dinas Kesehatan Kota Tomohon Provinsi Sulawesi Utara; Puskesmas Pangolombian Kota Tomohon dan Puskesmas Kakaskasen Kota Tomohon atas bantuan material dan waktu yang diberikan.

\section{Daftar Rujukan}

1. Komisi Nasional Lanjut Usia. Pedoman Pelaksanaan Posyandu Lansia. Jakarta: Komisi Nasional Lanjut Usia; 2010.

2. Kementerian Kesehatan RI. Pendekatan Siklus Hidup Dalam Pelayanan Kesehatan Lanjut Usia. Jakarta: Pusat Komunikasi Publik Sekretariat Jenderal Kementerian Kesehatan RI; 2014.

3. Roosheroe A. G. Tahun 2025, Jumlah Lansia Melebihi Balita; 2013. [Diakses 3 Juli 2016]. Terdapat pada https://lifestyle.kompas.com/ $\mathrm{read} / 2013 / 06 / 01 / 08561583 /$ Tahun.2025. Jumlah.Lansia.Melebihi.Balita.

4. Kementerian Kesehatan RI. Riset Kesehatan Dasar 2013. Jakarta: Balitbangkes; 2014

5. Kumar, $R$ dan M. Safee. Assessment of Morbidity Pattern And its Correlates Among Elderly Population in Rural Area of Perambalur, Tamilnadu, India, International Journal of Biomedical Research. 2014.

6. Haryanto J.T. Penduduk Lansia dan Bonus Demografi Kedua. Kementerian Keuangan Republik Indonesia; 2015. [diakses 8 Maret 2019]. Terdapat pada http://www.kemenkeu. go.id/Artikel/penduduk-lansia-dan-bonusdemografi-kedua.

7. Millman M. Access to health care in America. Institute of Medicine, Committee on Monitoring Access to Personal Health Care Services. Washington: National; 1993.

8. Dixon-Woods. M. at. al. Vulnerable groups and access to health care: a critical interpretive review. Leicester: University of Leicester; 2005. p.22-28.

9. Bierman A, Magari ES, Jette AM, et al. Assessing access as a first step toward improving the quality of care for very old adults. J Ambul Care Manage. 1998 Jul;121(3):17-26.

10. Notoatmodjo, S. Promosi Kesehatan dan Ilmu Perilaku. Cetakan I. Jakarta : PT. Rineka Cipta.; 2007.

11. Asla, T., Williamson, K., \& Mills, J. The role of information in succesful aging: the case for a research focus on the oldest old. Library \& Information Science Research: 2006; 28: 49-63.

12. Morey, O.T. Health information ties: preliminary findings on the health information seeking behavior of an African-American community. Information Research, 2007; [Diakses pada 14 January 2018]; 12(2): 277. Terdapat pada http://informationr.net/ir/12-2/paper297. html Archived by WebCite ${ }^{\circledR} a t$ http://www. webcitation.org/5d2DrUSZ5)

13. Stanley M, Beare PG. Buku ajar keperawatan gerontik. Edisi 2. Jakarta; 2007

14. Hunter D J \& Reddy K. Noncommunicable diseases. New England Journal of Medicine 369 2013: IHME (Institute for Health Metrics and Evaluation). DALY estimates for Australia; 1336-43

15. Nungky Kustantya \& Mochamad Saiful Anwar. Hubungan Tingkat Pengetahuan Dengan Perilaku Hidup Bersih Dan Sehat (Phbs) Pada Lansia. Jurnal Keperawatan 2013; 4(1)

16. Nugroho W. Perawatan Lanjut Usia, Jakarta: EGC; 1995.

17. Dadan, Mardian dan Priyana. Pengetahuan Lansia Tentang Dengan Motivasi Lansia Mengunjungi Posbindu. Depok: Fakultas Ilmu Keperawatan, Universitas Indonesia; 2016

18. Suryani I. Analisis akses masyarakat lanjut usia (Lansia) dalam pemanfaatan pelayanan kesehatan dasar gratis puskesmas di Kota Medan. [Tesis]. Depok: Fakultas Kesehatan Masyarakat UI; 2005.

19. Potter, P.A, Perry, A.G. Buku Ajar Fundamental Keperawatan: Konsep, Proses, dan Praktik. Komalasari R dkk, penerjemah. Edisi ke-4. Volume 2. Jakarta: EGC; 2005.

20. Nugroho W. Keperawatan Gerontik \& Geriatrik. Edisi 3. Jakarta: Penerbit Buku Kedokteran EGC; 2008.

21. Florentino, L., Datta, D., Gentle, S., Hall, D. M. B., Harpin, V., Phillips, D., \& Walker, A.Transition from school to adult life for physically disabled young people. Archives of Disabled Children 1998; 79; 306-311.

22. Kementerian Kesehatan. Pelayanan dan Peningkatan Kesehatan Usia Lanjut. Jakarta: 2015. [diakses tanggal 15 Desember 2017]. 
Tersedia pada: http://www.depkes.go.id/ article/print/15052700010/pelayanan-danpeningkatan-kesehatan-usia-lanjut.html

23. Departemen Kesehatan RI. Pedoman Pelatihan Kader Kelompok Usia Lanjut Bagi Petugas Kesehatan. Jakarta: Direktorat Kesehatan Keluarga; 2006.

24. Rooy, G. V., Mufune P., Amadhila E. Experiences and Perceptions of Barriers to Health Services for Elderly in Rural Namibia: A Qualitative Study. Sage Pub; 2015. [diakses 18 Maret 2019]. Tersedia pada https://journals.sagepub.com/doi/ full/10.1177/2158244015596049

25. Rowe J.W., Berkman L., Fried L., Fulmer T., Jackson J., Naylor M., Nove; llio W., Olshansky J., Stone R. Preparing for Better Health and Health Care for an Aging Population A Vital Direction for Health and Health Care; 2016. [Diakses 20 April 2019]. Tersedia pada https://nam.edu/wp-content/uploads/2016/09/ Preparing- for-Better-Health-and-HealthCare-for-an-Aging-Population.pdf

26. Towards age-friendly primary health care. Geneva: World Health Organization; 2004.

27. Soesanto E. Analisis Faktor Faktor Yang Berhubungan Dengan Praktik Lansia Hipertensi Dalam Mengendalikan Kesehatannya Di Puskesmas Mranggen Demak. FIKKES Jurnal
Keperawatan 2010;3(2): 98-108

28. Badan Perencanaan Pembangunan Nasional. Perlindungan Sosial Di Indonesia: Tantangan dan Arah ke Depan. Direktorat Perlindungan dan Kesejahteraan Masyarakat. Jakarta; 2014.

29. Soemiarti Dkk. Bunga Rampai Psikologi Perkembangan Pribadi Dari Bayi Sampai Lanjut Usia. Jakarta: Universitas Indonesia Press; 2001.

30. Hsia J, Kemper E, Sofaer S, et al. Is insurance a more important determinant of healthcare access than perceived health? Evidence from the Women's Health Initiative. J Womens Health Gend Based Med 2000;9:881-889.

31. Doescher MP, Saver BG, Franks P, Fiscella K. Racial and ethnic disparities in perception of physician style and trust. Arch Fam Med. 2000; 9:1156-1163.

32. Barman T. Social And Economic Empowerment of Older Persons In Myanmar Through Older People Self-Help Groups. HelpAge Myanmar; 2009.

33. Han M. Health care of the elderly in Myanmar. Regional Health Forum 2012;16(1).

34. Kementerian Kesehatan RI. Pedoman penyelenggaraan Corporate Social Responsibility (CSR) dalam Pembangunan Kesehatan, Jakarta; 2012. 